\title{
Simple, sensitive and specific quantification of diamine oxidase activity in complex matrices using newly discovered fluorophores derived from natural substrates
}

\author{
Thomas Boehm ${ }^{1}$ (1) - Matthias Karer ${ }^{1} \cdot$ Elisabeth Gludovacz ${ }^{1,2} \cdot$ Karin Petroczi $^{1} \cdot$ Marlene Resch $^{1}$. \\ Kornelia Schuetzenberger ${ }^{3} \cdot$ Kristaps Klavins $^{4} \cdot$ Nicole Borth $^{2} \cdot$ Bernd Jilma $^{1}$
}

Received: 26 February 2020 / Revised: 30 April 2020 / Accepted: 13 May 2020 / Published online: 1 June 2020

(c) The Author(s) 2020

\begin{abstract}
Objective To measure diamine oxidase (DAO) activity with high sensitivity in complex matrices like plasma or tissue extracts radioactive putrescine or horseradish peroxidase (HRP)/hydrogen peroxide $\left(\mathrm{H}_{2} \mathrm{O}_{2}\right)$ coupling must be used. The use of radioactive material should be avoided and $\mathrm{HRP} / \mathrm{H}_{2} \mathrm{O}_{2}$ coupling is compromised by antioxidants.

Methods and results Condensation of ortho-aminobenzaldehyde (oABA) with delta-1-pyrroline and delta-1-piperideine, the autocyclization products of the DAO-oxidized natural substrates putrescine and cadaverine, generates new quinazoline fluorophores with absorption and excitation maxima of 430 and $460 \mathrm{~nm}$, respectively, and peak emission at $620 \mathrm{~nm}$. Fluorescent-based detection limits are 20-40 times lower compared to absorption measurements. This assay can be used to measure DAO activity in human plasma after spiking recombinant human (rh)DAO, in rat plasma after intravenous rhDAO administration, in pregnancy plasma and in tissue extracts of DAO wild-type and knock-out mice. Using rat plasma the correlation between rhDAO activity and ELISA data is 99\%. Human and rat plasma without DAO spiking and tissue extracts from DAO knock-out mice showed stable and low fluorescence in the presence of high substrate concentrations.

Conclusions Incubation of DAO with the natural substrates putrescine and cadaverine and oABA generates novel fluorophores increasing the detection limit compared to absorption measurements at least tenfold. This simple, sensitive and specific assay allows the non-radioactive quantification of DAO activity in complex matrices like plasma and tissue extracts without interference by antioxidants.
\end{abstract}

Keywords Diamine oxidase $\cdot$ Ortho-aminobenzaldehyde $\cdot$ Fluorophore $\cdot$ Quinazoline

Responsible Editor: John Di Battista.

Electronic supplementary material The online version of this article (https://doi.org/10.1007/s00011-020-01359-5) contains supplementary material, which is available to authorized users.

Thomas Boehm

thomas.boehm@meduniwien.ac.at

1 Department of Clinical Pharmacology, Medical University of Vienna, Waehringer Guertel 18-20, 1090 Vienna, Austria

2 Department of Biotechnology, University of Natural Resources and Life Sciences, Muthgasse 18, 1190 Vienna, Austria

3 Center for Medical Physics and Biomedical Engineering, Medical University of Vienna, Waehringer Guertel 18-20, 1090 Vienna, Austria

4 CeMM Research Centre for Molecular Medicine of the Austrian Academy of Sciences, Lazarettgasse 14, 1090 Vienna, Austria

\section{Introduction}

Human diamine oxidase (E.C. 1.4.3.6) is a copper-containing amine oxidase that oxidatively deaminates histamine and various polyamines releasing ammonia and hydrogen peroxide [1]. It is an important enzyme in the extracellular catabolism of histamine and is highly expressed only in human intestine, kidney and fetal extravillous trophoblast cells [2-4].

For many decades the state of the art assay to measure DAO activity was based on autocyclization of radioactively-labelled putrescine or cadaverine followed by organic extraction and radioactivity measurements [5]. This assay is sensitive and specific, but working with radioactivity is expensive and not welcomed in the modern laboratory environments. It was also possible to measure serum DAO activity in non-pregnant healthy individuals 
[6]. A commercial assay using tritiated putrescine is available, but not suitable for DAO activity quantifications. We measured poor linearity using recombinant human (rh) DAO, possibly because the substrate concentration is several thousand-fold below the $\mathrm{K}_{\mathrm{m}}$ to limit radioactivity exposure [7]. Lower DAO activity might be measured in tissue extracts with high capacity to convert the putrescine oxidation product gamma-aminobutyraldehyde into water soluble gamma-aminobutyric acid [8]. Bardsley [9] used para-dimethylaminomethylbenzylamine as DAO substrate but the affinity of this substrate is low [1] and the assay is not suitable for complex matrices, because the resulting aldehyde is directly measured at $250 \mathrm{~nm}$ and at this wavelength many interfering substances are present in tissue extracts or plasma.

In 1936 it was described that the condensation of orthoaminobenzaldehyde (oABA) and delta-1-pyrroline, the autocyclized DAO oxidation product of putrescine, generates a yellow-orange chromophore [10]. This reaction can be used to measure DAO activity [11]. Nevertheless, the sensitivity is relatively low, because the extinction coefficient of the quinazoline chromophore is only $1860 \mathrm{M}^{-1} \mathrm{~cm}^{-1}$ and many substances interfere in complex matrices like tissue extracts or plasma at the absorption peak of $430 \mathrm{~nm}$. This assay can be used to measure DAO activity in plasma during the second and third trimester, but not in non-pregnant individuals [12].

Diamine oxidase activity was also measured in tissue extracts using hydrogen peroxide $\left(\mathrm{H}_{2} \mathrm{O}_{2}\right)$ /horseradish peroxidase (HRP)/homovanillic acid coupling [13], but abundant antioxidants and $\mathrm{H}_{2} \mathrm{O}_{2}$ degrading enzymes like catalase might interfere significantly. The sensitivity of this assay using small intestinal protein extracts was comparable to the radioactive putrescine method. Schwelberger and Feurle (2007) exchanged homovanillic acid with luminol [14]. They wrote that this luminescence assay was as sensitive as the radioactive putrescine method, but they never used complex matrices like plasma or tissue extracts to compare detection limits [14]. It is likely that in particular the high serum or plasma antioxidative capacity of approximately $800 \mu \mathrm{M}$ will significantly interfere with measuring plasma DAO activity using $\mathrm{HRP} / \mathrm{H}_{2} \mathrm{O}_{2}$ coupling [15].

We recently published the development and characterization of a human DAO ELISA with limits of detection and quantification of below $1 \mathrm{ng} / \mathrm{ml}$ [7]. Nevertheless, DAO released from heparan-sulfate proteoglycans during severe mast cell activation events in mastocytosis patients reached concentrations of several hundred $\mathrm{ng} / \mathrm{ml}$, but DAO activity using the histamine degradation rate was clearly compromised compared to DAO in plasma during pregnancy [16]. Several approved medications have been described as DAO inhibitors [17]. The identification and characterization of clinically relevant DAO inhibitors will be easier if we are able to measure not only antigen concentrations but also corresponding activity.

The main limitation of current non-radioactive DAO activity assays is sensitivity and compatibility with the high antioxidant capacity of plasma. A fluorescence assay might provide the necessary increase in sensitivity. Based on the chemical structures of various fluorescent molecules such as resorufin, acridine or methylene blue we hypothesized that the triple aromatic ring generated by the condensation of delta-1-pyrroline or delta-1-piperideine with oABA is not only a chromophore but also a fluorophore.

Here, we describe the development and characterization of a novel, simple and sensitive fluorescence assay to measure DAO activity in complex matrices like plasma or tissue extracts using the natural DAO substrates cadaverine and putrescine.

\section{Experimental methods}

\section{DAO activity measurements using hydrogen peroxide $\left(\mathrm{H}_{2} \mathrm{O}_{2}\right)$ /horseradish peroxidase (HRP)/ luminol coupling}

The DAO activity assay used in Figs. 1 and $\mathrm{S} 1$ is based on the luminescence assay published by [14]. We used $110 \mu \mathrm{l}$ final volume in white luminescence plates (Porvair; Graz, Austria), which are composed of $50 \mu \mathrm{l}$ serum or plasma treated as described below and $50 \mu \mathrm{l}$ luminol solution from a commercial western blotting ECL kit (Amersham RPN2106; Vienna, Austria) containing $2 \mu \mathrm{g} / \mathrm{ml}$ horseradish peroxidase (HRP; P6782; Sigma-Aldrich; Vienna, Austria). The reaction was started with the addition of $10 \mu \mathrm{l}$ substrate solution at a final concentration of $360 \mu \mathrm{M}$. The RLUs were measured in a Victor2 ${ }^{\mathrm{TM}} 1420$ Microtiter Plate Reader (Perkin Elmer; Vienna, Austria). All samples were measured in duplicate and the mean is shown. Final DAO concentrations were $0.5-2 \mu \mathrm{g} / \mathrm{ml}$, quantified using a DAO ELISA which has been developed in-house [7]. We did not see relevant differences, regardless of whether DAO was added before uricase/ascorbase (UA) and butanol/diisopropylether (BD) treatment or afterwards (data not shown; see below for UA and $\mathrm{BD}$ description). The expression and characterization of rhDAO in Chinese hamster ovary $(\mathrm{CHO})$ cells has been published [18]. In some experiments we used directly 10-20-fold concentrated CHO supernatant. There was no relevant difference in the enzyme characteristics between purified or supernatant DAO (data not shown). Pig kidney DAO (D7876), putrescine (P5780), cadaverine (C8561), histamine (53300) and ortho-aminobenzaldehyde (A9628) were purchased from Sigma-Aldrich (Vienna, Austria). Uricase (URIC-70-1701; Sekisui Enzymes; Kings Hill, UK) at 30 $\mathrm{U} / \mathrm{ml}(30 \times)$ and ascorbase (70-6141-20 or T-53; Sekisui 


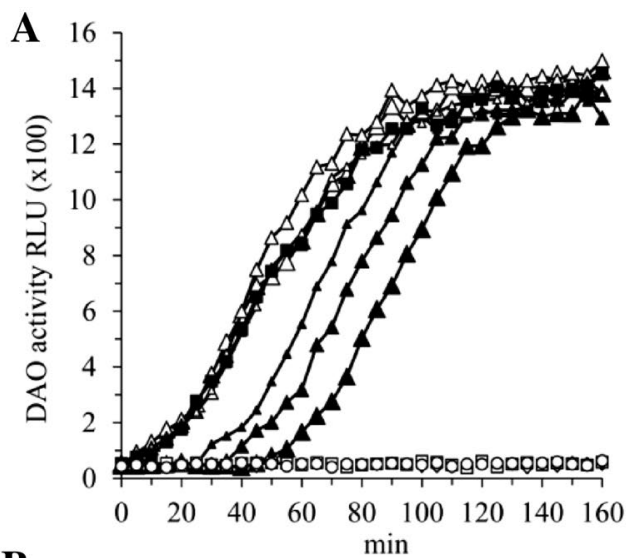

B

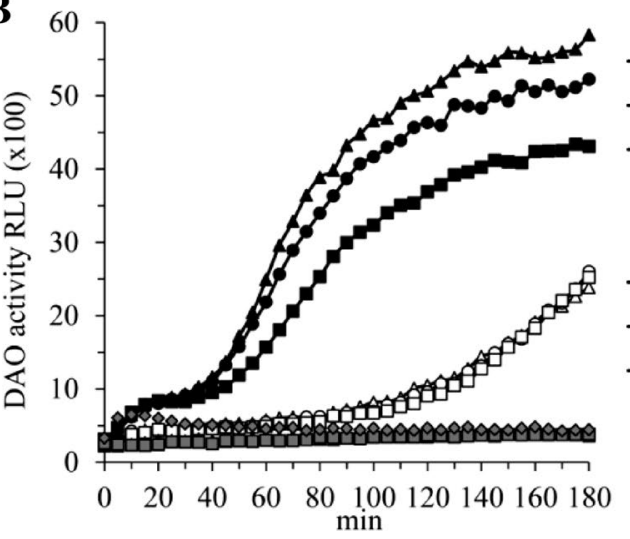

C

- W/ODAO

$\square \mathrm{w} / \mathrm{DAO}$

\pm U_200

$\pm U_{-} 100$

- U_50

-与UA_200

-5 UA_100

$--U A \_50$

$\rightarrow-U$

○ UA_w/oDAO

D

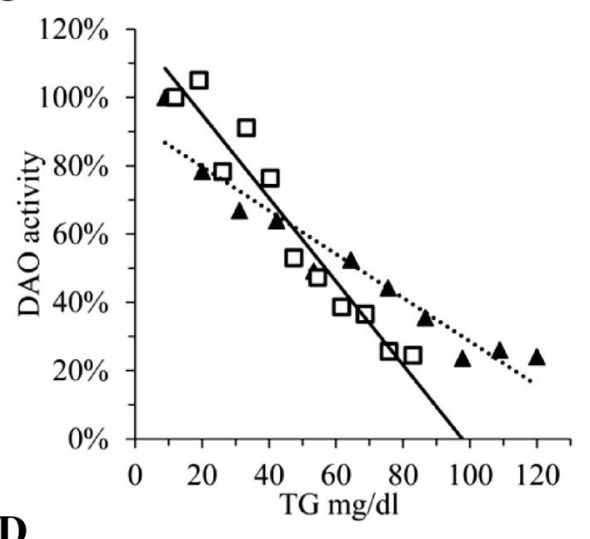

$-5 \mathrm{HL} 3$ UA

- - HL4_UA

- -UA

$\triangle$ UA_w/oDAO

- W/oUABD

\pm HL3_UABD

$\rightarrow$ HL4_UABD

$\rightarrow$ UABD

-UABD_w/oDAO

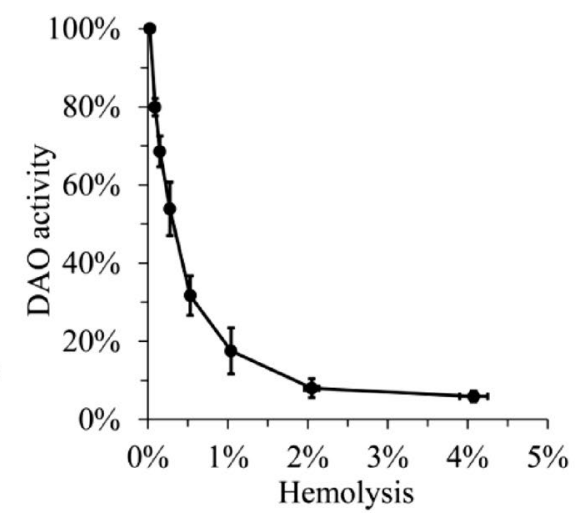

Fig. 1 Plasma and serum DAO activity cannot be precisely measured using hydrogen peroxide $\left(\mathrm{H}_{2} \mathrm{O}_{2}\right)$ /horseradish peroxidase (HRP)/ luminol coupling. a Human serum with and without rhDAO spiking was left untreated or treated with $1 \mathrm{U} / \mathrm{ml}$ uricase $(\mathrm{U})$ and $5 \mathrm{U} / \mathrm{ml}$ ascorbase (a) with or without addition of 200,100 or $50 \mu \mathrm{M}$ ascorbic acid; w/o DAO means without rhDAO spiking; rhDAO was spiked before addition of enzymes or ascorbic acid; $\mathbf{b}$ rhDAO activity was measured in UA treated human serum (concentrations of triglycerides [TG] 64 and cholesterol [CHOL] $157 \mathrm{mg} / \mathrm{dl}$ ) without or after mixing with hyperlipidemic sera HL3 and HL4 (final concentrations TG 573, 318 and CHOL 199, 178 mg/dl, respectively). Lipids were extracted using butanol/diisopropylether (BD) as indicated; c Two EDTA plasma samples from two healthy volunteers were spiked with rhDAO and either treated with UA or both UA and BD. Autologous

Enzymes; Kings Hill, UK) at $100 \mathrm{U} / \mathrm{ml}(40 \times)$, stocks were stored at $-32{ }^{\circ} \mathrm{C}$ in single use aliquots and serum or plasma samples were pre-treated for $15 \mathrm{~min}$ at $37{ }^{\circ} \mathrm{C}$. PBS was added to non-treated samples. Ascorbic acid (20×; A4544, Sigma-Aldrich; Vienna, Austria) was freshly dissolved in PBS (Gibco; Vienna, Austria). Butanol/diisopropylether lipid extraction was performed according to [19]. Briefly, 2 volumes of 1-butanol (281,549, Sigma-Aldrich; Vienna, Austria) and diisopropylether (38270, Honeywell; Vienna, Austria) at a ratio of 40-60 were added to 1 volume of serum or plasma and end-over-end rotated for $45 \mathrm{~min} .250 \mu \mathrm{M}$ EDTA was added to serum samples only. After extraction the mixture was centrifuged at $2000 \mathrm{rpm}$ for $2 \mathrm{~min}$ and the
UA/non-treated and UA/BD-treated plasma was consequently mixed at various ratios obtaining triglyceride (TG) concentrations between 10 and $120 \mathrm{mg} / \mathrm{dl}$. The DAO activities were normalized based on activity in UA/BD treated serum. The $R$ values were in both regression lines > 0.96; $\mathbf{d}$ rhDAO was spiked into EDTA plasma from two donors containing different concentrations of autologous red blood cell lysate diluted in autologous plasma. All samples were treated with UA/BD. The mean $(+/-\mathrm{SEM})$ percent DAO activity determined in duplicates and the mean $(+/-$ SEM) percent hemolysis of the two plasma samples are plotted. In all panels DAO activity was measured using $\mathrm{H}_{2} \mathrm{O}_{2} / \mathrm{HRP} /$ luminol coupling and the mean relative light units (RLU) of duplicates or percentage of DAO activity normalized to the appropriate controls are shown

aqueous (lower) phase was removed carefully. Triglyceride (TG) and cholesterol (CHOL) concentrations were reduced more than tenfold with unchanged protein concentrations [7, 19]. Triglycerides and CHOL were measured using standard methods in the clinical chemistry laboratories at the General Hospital Vienna.

\section{Preparation of red blood cell lysates}

Whole blood anti-coagulated with EDTA was mixed with 1.5 volumes of erylysis buffer and incubated for $5 \mathrm{~min}$ at room temperature. Following centrifugation for $10 \mathrm{~min}$ at $4{ }^{\circ} \mathrm{C}$ and $350 \mathrm{~g}$ the supernatant was collected. This contained 
more than $90 \%$ of the total hemoglobin. The erylysis buffer consisted of $155 \mathrm{mM}$ ammonium chloride, $100 \mu \mathrm{M}$ EDTA and $10 \mathrm{mM} \mathrm{KHCO}_{3}(\mathrm{pH}=7.4)$. Autologous plasma was used to dilute the lysate. The hemoglobin concentrations were measured with the QuantiChrom kit (BioAssay Systems; QHB-Kit, Hayward; CA) or at the clinical chemistry laboratories at the General Hospital Vienna.

\section{Synthesis of THPQ (delta-1-pyrroline/oABA condensate) and HHPQ (delta-1-piperideine/oABA condensate)}

Two $\mu \mathrm{g} / \mathrm{ml}$ purified rhDAO, $400 \mu \mathrm{M}$ substrates and $1 \mathrm{mM}$ ortho-aminobenzaldehyde (oABA; stored at $-32{ }^{\circ} \mathrm{C}$ for 4-6 months as a $200 \mathrm{mM}$ stock solution in absolute ethanol) in $20 \mathrm{mM}$ Hepes at $\mathrm{pH} 7.0$ containing $0.05 \%$ human serum albumin (20\% Octapharma; Vienna, Austria) were incubated for $2 \mathrm{~h}$ at $37{ }^{\circ} \mathrm{C}$. This oABA concentration leads to $83 \mathrm{mM}$ ethanol in the samples, which does not influence DAO activity. The solutions were filtered through Amicon 3000 MWCo devices before absorption and fluorescence measurements. The condensate between delta-1-pyrroline (3,4-dihydro- $2^{\mathrm{H}}$-pyrrole) and oABA generates $2,3,3 \mathrm{a}, 4$ tetrahydro- $1^{\mathrm{H}}$-pyrrolo[2,1- ${ }^{\mathrm{b}}$ ]quinazoline-10-ium (IUPAC name). This is abbreviated as THPQ. Incubation of delta1-piperideine (2,3,4,5-tetrahydro-pyridine) and oABA generates $5,5 \mathrm{a}, 6,7,8,9$-hexahydropyrido[2,1-b $]$ quinazoline10-ium or HHPQ.

\section{Absorption and fluorescence measurements}

Absorption was measured in a Synergy ${ }^{\mathrm{TM}} \mathrm{H} 1$ Multi-Mode Microplate reader (BioTek; Winooski, Vermont, US) and scans were performed using 4 or $8 \mathrm{~nm}$ steps. The resolution of the Synergy ${ }^{\mathrm{TM}} \mathrm{H} 1$ for absorbance measurements is 0.0001 optical density units. UV-compatible 96-well half-area flat bottom microplates (CLS3635 Corning ${ }^{\circledR}$ UV-Transparent Microplates; Sigma-Aldrich; Vienna, Austria) were used with a total reaction volume of $170 \mu \mathrm{l}$, corresponding to a light path of $1 \mathrm{~cm}$.

Relative fluorescence units (RFUs) were measured with a Synergy ${ }^{\mathrm{TM}} \mathrm{H} 1$ Multi-Mode Microplate reader using either a custom filter cube or the monochromator module. The custom filter cube is composed of an excitation filter $440 / 30 \mathrm{~nm}$ (range 425-455 nm), a dichroic mirror (DM) with a cut-off of $550 \mathrm{~nm}$ and an emission filter of $620 / 40 \mathrm{~nm}$ (range 600-640 nm). This filter set was selected based on the absorption maximum of the condensation product of delta1-pyrroline with oABA at $440 \mathrm{~nm}$. A filter with an excitation maximum at $460 \mathrm{~nm}$ (range $440-480 \mathrm{~nm}$ ) might increase the sensitivity for measuring HHPQ, because the area under the curve (AUC) for absorption by the delta-1-piperideine/ oABA fusion product (HHPQ) is increased by about $50 \%$, whereas the control AUCs or THPQ AUCs are unchanged switching from the 440 to $460 \mathrm{~nm}$ filter set (data not shown). We tested such a filter and the fluorescence was increased by $43 \%$ (data not shown). Emission scans were performed using 4 or $8 \mathrm{~nm}$ steps with excitation at $460 \mathrm{~nm}$ and emission scans from 500 to $700 \mathrm{~nm}$. For excitation scans we used fixed emission at $620 \mathrm{~nm}$ after excitation from 350 to $580 \mathrm{~nm}$. For fluorescent measurements we measured a volume of 100 or $200 \mu \mathrm{l}$ using either black or clear bottom black fluorescent plates $\left(3915,3615\right.$ or 3904 Corning-Costar ${ }^{\circledR} 96-$-well Black Flat Bottom Polystyrene microplates; Szabo-Scandic; Vienna, Austria).

For the detection of HHPQ (delta-1-piperideine/oABA condensate) in plasma from healthy volunteers or third trimester pregnancies we mixed $90 \mu \mathrm{l}$ plasma adjusted to $\mathrm{pH}$ 7.0 with $13 \mu \mathrm{l} 1 \mathrm{M} \mathrm{HCl}$ per ml of plasma with $5 \mu \mathrm{l} 10 \%$ ethanol or $5 \mu \mathrm{l} 20 \mathrm{mM}$ oABA and $5 \mu \mathrm{l} \mathrm{PBS}$ or $5 \mu \mathrm{l} 4 \mathrm{mM}$ cadaverine. All samples were analyzed in duplicate. After $1 \mathrm{~h}$ incubation at $37{ }^{\circ} \mathrm{C}$ in the dark, $200 \mu \mathrm{l} 7.5 \%$ TCA $(99.5 \%$ trichloroacetic acid; 91228; Sigma-Aldrich; Vienna, Austria) was added and incubated for $20 \mathrm{~min}$ on ice. After high speed centrifugation for $10 \mathrm{~min}, 200 \mu \mathrm{l}$ were recovered and the $\mathrm{pH}$ adjusted to 4.0 with $5.2 \mu \mathrm{l} 10 \mathrm{M} \mathrm{NaOH}$ and $50 \mu \mathrm{l}$ $500 \mathrm{mM}$ citrate buffer $\mathrm{pH}$ 4.0. TCA precipitation reduced protein autofluorescence by approximately sevenfold (data not shown).

\section{Determination of absorption and fluorescence $\mathrm{pH}$ dependency using the Britton Robinson buffer}

The Britton-Robinson buffer (BRB) contains a final concentration of $40 \mathrm{mM}$ acetic acid, $40 \mathrm{mM} \mathrm{H}_{3} \mathrm{PO}_{4}$ and $40 \mathrm{mM}$ boric acid and the $\mathrm{pH}$ was adjusted with $\mathrm{NaOH}$ from $\mathrm{pH} 2$ to $\mathrm{pH} 12$ [20]. Synthesized THPQ and HHPQ were diluted with the BRB buffer 13.3-fold to $30 \mu \mathrm{M}$ and absorption and fluorescence measured. The BRB buffer contains different ionic strengths after $\mathrm{pH}$ adjustment. The ionic strength at $\mathrm{pH}$ 2 is 0.02 , at $\mathrm{pH} 8=0.095$ and increases to 0.128 at $\mathrm{pH} 12$. We, therefore, also tested whether increased $\mathrm{NaCl}$ concentrations influence fluorescence of THPQ and HHPQ.

\section{HHPQ and resorufin generation in PBS containing $0.05 \%$ HSA}

For the direct comparison of HHPQ and resorufin generation using different rhDAO concentrations (Fig. 5) we used the conditions discussed below. For HHPQ, $170 \mu \mathrm{PBS}$ with $0.05 \%$ HSA, $10 \mu \mathrm{l}$ of different rhDAO concentrations and $10 \mu \mathrm{l} 20 \mathrm{mM}$ oABA were mixed. For Amplex Red oxidation, $170 \mu \mathrm{l}$ PBS with $0.05 \%$ HSA and $1 \mu \mathrm{g} / \mathrm{ml} \mathrm{HRP}, 10 \mu \mathrm{l}$ of different rhDAO concentrations and $10 \mu \mathrm{l} 2 \mathrm{mM}$ Amplex Red were mixed. The reactions were started via the addition of $10 \mu \mathrm{l} 2 \mathrm{mM}$ cadaverine or PBS and incubated at $37^{\circ} \mathrm{C}$. 
Under these conditions direct measurements within the microplate reader are possible with low autofluorescence. Absorption of HHPQ and resorufin were measured using $460 \mathrm{~nm}$ and $570 \mathrm{~nm}$, respectively, and fluorescence using the custom filter cube (Ex440 $\pm 30 / \mathrm{DM} 550 / E m 620 \pm 20)$ or Ex550/Em590 for resorufin using the monochromator module with $16 \mathrm{~nm}$ bandwidth. All samples were run in duplicate.

\section{$H H P Q$ and resorufin generation in EDTA plasma}

For the direct comparison of HHPQ and resorufin generation using different rhDAO concentrations in plasma (Fig. 6a, b) we used the following conditions: For HHPQ, $85 \mu \mathrm{LDTA}$ plasma, $5 \mu \mathrm{l}$ of different concentrations of rhDAO and $5 \mu \mathrm{l}$ $20 \mathrm{mM}$ oABA or $5 \mu \mathrm{l} 10 \%$ ethanol (oABA matrix) were mixed. For Amplex Red oxidation $85 \mu 1$ EDTA plasma containing $1 \mu \mathrm{g} / \mathrm{ml} \mathrm{HRP}, 5 \mu \mathrm{l}$ of different concentrations of rhDAO and $5 \mu \mathrm{m} 2 \mathrm{mM}$ Amplex Red or 10\% DMSO (Amplex Red matrix) were mixed. The reactions were started via the addition of $5 \mu \mathrm{L} 2 \mathrm{mM}$ cadaverine or PBS and incubated for $3 \mathrm{~h}$ at $37{ }^{\circ} \mathrm{C}$ in the dark. After the incubation period TCA precipitation was performed as described above. The HHPQ samples were adjusted to $\mathrm{pH} 4.0$ using $50 \mu \mathrm{l}$ of $500 \mathrm{mM}$ citrate buffer and the resorufin samples to $\mathrm{pH} 7.8$ using $50 \mu \mathrm{l}$ of $500 \mathrm{mM}$ potassium phosphate buffer $\mathrm{pH}$ 8.0. Resorufin fluorescence is reduced below $\mathrm{pH}$ 7.0. Absorption and fluorescence were measured as described above.

\section{Administration of rhDAO to rats and fluorescence-based DAO activity measurements}

The experimental protocols for mice and rats were approved by the local Animal Welfare Committee and the Federal Ministry of Science, Research and Economy (Vienna; Austria) and conducted in full accordance with the ARRIVE guidelines [21]. The exact procedure of inserting a vascular access port into the Vena jugularis (Rodent Vascular Access Port with detachable Silastic Catheter, Hugo-Sachs Electronic Harvard Apparatus; Germany) and the standardized housing conditions at the Animal Care Facility at the Department for Biomedical Research, Medical University Vienna, will be described elsewhere.

Recombinant $\mathrm{hDAO}$ expressed and purified as described [18] was injected into approximately $400 \mathrm{~g}$ rats in a volume of $600 \mu \mathrm{l}$ PBS at $1 \mathrm{mg} / \mathrm{kg}$. At the indicated timepoints $500 \mu \mathrm{l}$ blood was drawn and anticoagulated with citrate. Sodium chloride was used to replace the blood volume. After preparation of plasma samples were stored at $-32{ }^{\circ} \mathrm{C}$. Rat plasma was diluted $1-10$ using $0.05 \%$ HSA in PBS and DAO activity measured as described above for plasma samples. Cadaverine was used as substrate and HHPQ detection was performed using the custom filter cube. Human DAO antigen concentrations were determined using a DAO ELISA [7].

\section{Preparation of protein extracts from DAO wild-type and knock-out mice}

Diamine oxidase deficient mice were generated from frozen embryos obtained from the European Mouse Mutant Archive. Mice were kept according to the animal protocol GZ 66.009/0160-WF/V/3b/2016 which has been approved by the Austrian Agency for Health and Food Safety. Organs were harvested on ice and slices of $20-100 \mathrm{mg}$ were immediately frozen in liquid nitrogen. Tissue pieces were added to 10 volumes of ice-cold $20 \mathrm{mM}$ potassium phosphate buffer ( $\mathrm{pH}$ 7.2) supplemented with $0.5 \%$ proteinase inhibitor cocktail (P8340, Sigma-Aldrich; Vienna, Austria) and homogenized at $3000 \mathrm{rpm}$ for $1 \mathrm{~min}$ using Lysing Matrix tubes E (116914050, MP Biomedicals; Eschwege, Germany) and the Precellys 24 tissue homogenizer (432-3750, VWR; Vienna, Austria). Tissue homogenates were centrifuged at $12,000 \mathrm{~g}$ at $4{ }^{\circ} \mathrm{C}$ for $20 \mathrm{~min}$ and protein content of the supernatants was measured using the QuantiPro BCA Assay Kit (QPBCA-1KT, Sigma Aldrich; Vienna, Austria). Protein concentrations of tissue supernatants ranged between 5 and $18 \mathrm{mg} / \mathrm{ml}$.

$85 \mu \mathrm{l}$ of protein extracts diluted with potassium phosphate buffer to $500 \mu \mathrm{g} / \mathrm{ml}$ were used for the fluorescence assay as described above for plasma samples. A final concentration of $20 \mu \mathrm{M}$ aminoguanidine (AG) was used as a potent irreversible DAO inhibitor. If other enzymes without a topaquinone in the active center are able to oxidize cadaverine, the fluorescence without substrate and with substrate and AG should be different. The hydrazine group of AG covalently binds to the topaquinone, and $20 \mu \mathrm{M}$ AG irreversibly inhibits DAO activity by more than $95 \%$ (data not shown). If DAO is the only enzyme able to deaminate cadaverine generating delta-1-piperideine, the fluorescence between the samples without substrate and AG should be similar.

\section{Ethics}

The study numbers for the collection of blood samples from healthy volunteers and women in their third trimester are EC:2030/2013, EC:1810/2015 and EC:1666/2012. All healthy volunteers provided their informed consent before the collection of blood samples. All procedures were performed in accordance with the ethical standards of the responsible committee on human experimentation (institutional and national) and the 1975 Declaration of Helsinki (2013 revised edition). 


\section{Results}

In 2007 Schwelberger and Feurle published that $\mathrm{H}_{2} \mathrm{O}_{2} /$ HRP/luminol coupling is as sensitive as the state of the art DAO activity assay using radioactive putrescine [14]. Nevertheless, the performance of the luminescence assay in complex matrices such as plasma or tissue extracts has not been described. When we spiked rhDAO into human serum, no luminescence could be measured (Fig. 1a). After treatment with uricase, $50 \%$ of the peak DAO activity was present after 40 min (Fig. 1a). Different concentrations of ascorbic acid delayed the appearance of DAO activity, which could be overcome by adding ascorbase to the assay reaction mixture (Fig. 1a). Because $\mathrm{H}_{2} \mathrm{O}_{2}$ readily diffuses through lipid membranes [22], we hypothesized that $\mathrm{H}_{2} \mathrm{O}_{2}$ might diffuse into the abundant lipoprotein particles, thus escaping oxidation by HRP. Consequently, disrupting the lipid particles using butanol/diisopropylether (BD) lipid extraction should result in faster appearance of the DAO activity signal. Human serum treated with uricase (U) and/ or ascorbase (A) and after lipid extraction (BD) allowed fast measurement of pig kidney DAO (Fig. S1), but also of rhDAO activity (Fig. 1b). There was a strong negative correlation between DAO activity and triglyceride concentrations (Fig. 1c). The 50\% inhibitory concentration was approximately $60 \mathrm{mg} / \mathrm{dl}$, which is present in most human plasma samples. Finally, as expected, hemolysis severely interferes with $\mathrm{H}_{2} \mathrm{O}_{2} / \mathrm{HRP} /$ luminol coupling with an IC50 of approximately $0.3 \%$ hemolysis or a hemoglobin concentration of $460 \mu \mathrm{g} / \mathrm{ml}$ assuming $150 \mathrm{mg} / \mathrm{ml}$ hemoglobin concentration in whole blood (100\%) (Fig. 1d). Hemolysis might be less of an issue with human serum or plasma samples, but red blood cells from rat or mice hemolyze more easily, severely compromising $\mathrm{H}_{2} \mathrm{O}_{2} / \mathrm{HRP} /$ luminol coupling as method for DAO activity measurements. In addition, BD lipid extraction is not without pitfalls. First, peroxides accumulate in diisopropylether. Second, the solubility of butanol in water is $1 \mathrm{M}$ or $7.7 \%$, partially interfering with the DAO activity measurements (data not shown) and third, organic solvents are not environmentally friendly. In conclusion, an $\mathrm{H}_{2} \mathrm{O}_{2} / \mathrm{HRP} /$ luminol-coupled DAO activity assay is not suitable for the measurement of plasma or serum DAO oxidation capacity.

Holmsted and Tham (1959) measured DAO activity using absorption measurement of the chromophore obtained after condensation of oABA with autocyclized delta-1-pyrroline at $430 \mathrm{~nm}$ [11] (Fig. S2). Nevertheless, the relatively low extinction coefficient of the delta1-pyrroline /oABA condensate $\left(1860 \mathrm{M}^{-1} \mathrm{~cm}^{-1}\right)$ limits assay sensitivity. Human plasma absorption at $430 \mathrm{~nm}$ was 1.2-1.8 measuring three samples from healthy volunteers, precluding absorption measurements using minimally diluted plasma (data not shown).
Because several fluorescence compounds are linear triple aromatic ring structures, we hypothesized that the condensation product of delta-1-pyrroline (3,4-dihydro- $2^{\mathrm{H}}$-pyrrole) with oABA 2,3,3a,4-tetrahydro- $1^{\mathrm{H}}$-pyrrolo[2,1- $\left.{ }^{\mathrm{b}}\right]$ quinazoline-10-ium (THPQ) or the condensation product of delta-1-piperideine (2,3,4,5-tetrahydro-pyridine) with oABA 5,5a,6,7,8,9-hexahydropyrido[2,1-b ${ }^{\text {b }}$ quinazoline10-ium (HHPQ) (Fig. S2) are not only chromophores but also fluorophores. Figure 2 shows the absorption and fluorescent profiles of freshly synthesized HHPQ and THPQ in buffer matrix at $\mathrm{pH}$ 7.0. Peak absorption of THPQ and HHPQ at 430 and $460 \mathrm{~nm}$, respectively, coincide with the excitation maxima. The emission maxima are comparable at approximately $620 \mathrm{~nm}$ for both compounds. The calculated extinction coefficient for HHPQ is $2242 \mathrm{M}^{-1} \mathrm{~cm}^{-1}$ compared to $1860 \mathrm{M}^{-1} \mathrm{~cm}^{-1}$ for THPQ. Although the extinction coefficient of HHPQ is only increased by $17 \%$, the fluorescence signal is consistently 200 to $250 \%$ higher. The predicted molecular weights of $173 \mathrm{Da}$ for THPQ and $187 \mathrm{Da}$ for HHPQ with corresponding MS2 fragments have been verified, supporting the proposed structures (Fig. S3).

We also incubated rhDAO with histamine to see whether imidazole acetaldehyde or histamine per se is undergoing condensation with oABA. It is known that histamine fuses with o-phthalaldehyde to form ill-characterized fluorophores [23-25]. Histamine or imidazole acetaldehyde likely fuses with $\mathrm{OABA}$, because the $\mathrm{oABA}$ signal is consistently higher in the presence of histamine but there is no obvious wavelength shift and no fluorescence signal (Fig. 2b). Nevertheless, after a few days of storage histamine per se and imidazole acetaldehyde generated with rhDAO showed a specific fluorescence signal. The highest signal with imidazole acetaldehyde was obtained during storage at $-32{ }^{\circ} \mathrm{C}$. This "histamine peculiarity" is described in the Supplement (Text and Fig. S7). A specific and sensitive assay to trap generated imidazole acetaldehyde would be interesting, because no sensitive methods have been described to measure imidazole acetaldehyde specifically. However, as we have described in the Supplement, histamine also generates a fluorescence signal and the signal with imidazole acetaldehyde at room temperature and $4{ }^{\circ} \mathrm{C}$ is at least tenfold lower compared to HHPQ, although specific over histamine at these temperatures (Fig. S7). Neither spermidine nor spermine generated a chromophore or a fluorophore after incubation with DAO and oABA, although both endogenous polyamines are substrates for DAO (data not shown).

The Britton Robinson buffer system between $\mathrm{pH} 2$ and $\mathrm{pH} 12$ was used to measure the $\mathrm{pH}$ dependency of the absorption and fluorescence intensity of THPQ and HHPQ (Fig. 3). The pKa values for THPQ and HHPQ for absorption and fluorescence were approximately 10.5, 9.5 and 9.0, 8.5 , respectively. These two fluorophores could repeatedly be excited and measured at $\mathrm{pH}$ values below 7 (Fig. S4A 

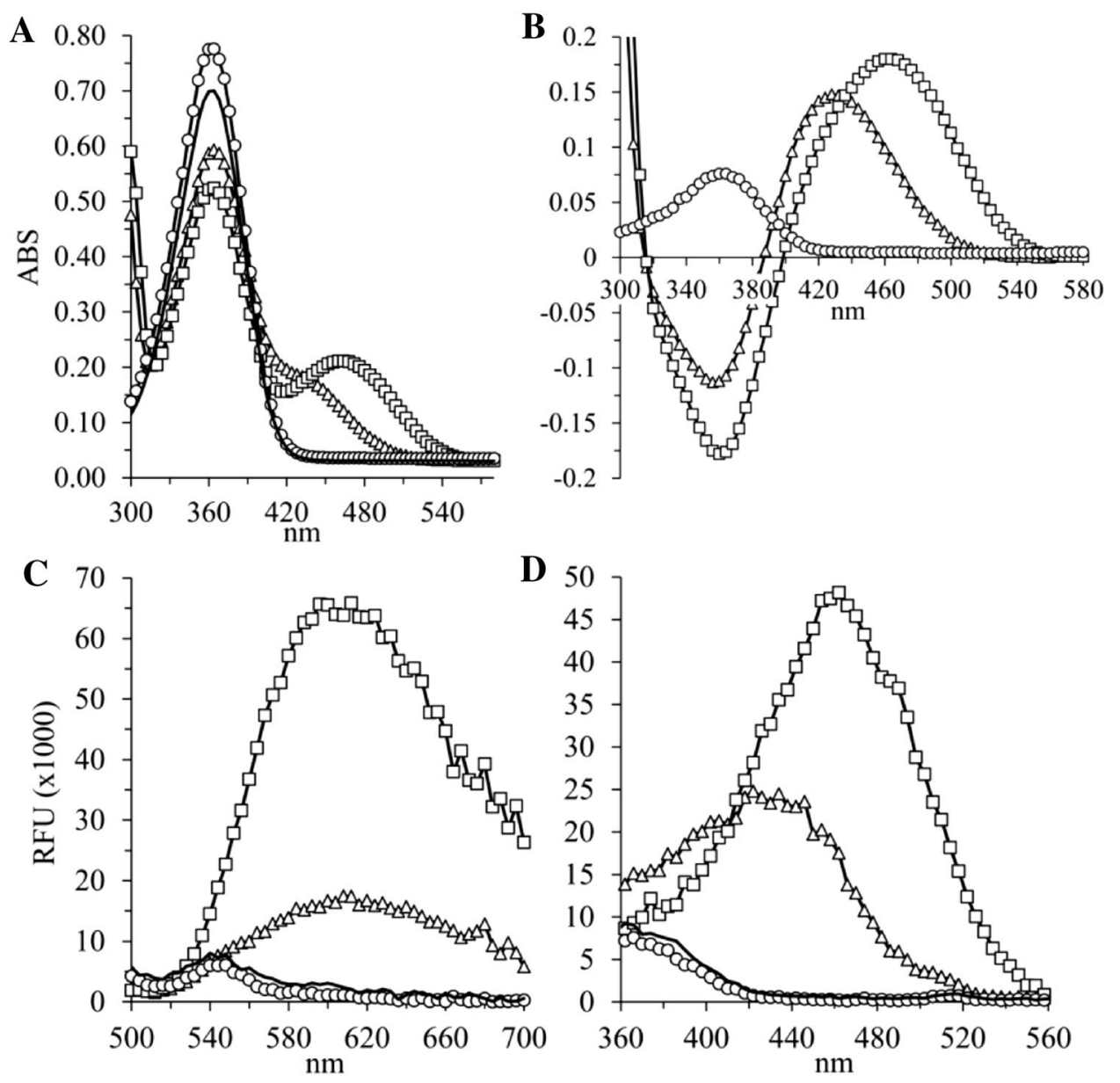

D 50

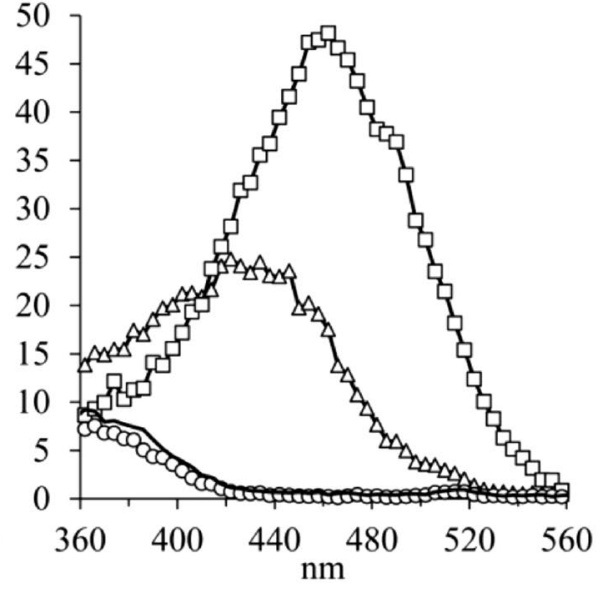

Fig. 2 The condensates of oABA with delta-1-pyrroline (THPQ) or delta-1-piperideine (HHPQ) are not only quinazoline chromophores but also novel fluorophores. Two $\mu \mathrm{g} / \mathrm{ml}$ purified rhDAO in $20 \mathrm{mM}$ Hepes (pH 7.0) containing $0.05 \%$ human serum albumin (HSA) was incubated for $2 \mathrm{~h}$ at $37{ }^{\circ} \mathrm{C}$ with $1 \mathrm{mM}$ ortho-aminobenzaldehyde (oABA) and $400 \mu \mathrm{M}$ putrescine, cadaverine, histamine or Hepes buffer followed by ultrafiltration using a $3 \mathrm{kDa}$ MWCO device; a Absorption (ABS) was measured from 300 to $700 \mathrm{~nm}$ after fivefold

and B). Fluorescence intensity was not influenced by up to $500 \mathrm{mM} \mathrm{NaCl}$ concentration (Fig. S4C). The polar protic solvents water followed by ethanol and methanol are the preferred matrices, in contrast to the aprotic polar solvents acetone and DMSO, which severely interfered with fluorescence signal intensity measurements (Fig. S4D, E).

THPQ and HHPQ also generated new absorption peaks at $246 \mathrm{~nm}$ (data not shown) and $290 \mathrm{~nm}$ (Fig. 2a), but the signal to noise ratios after excitation at $246 \mathrm{~nm}$ or $290 \mathrm{~nm}$ are lower compared to $430 / 460 \mathrm{~nm}$. Further characterization of the absorption and fluorescence properties of THPQ and HHPQ will be described elsewhere.

In the next experiments we determined the detection limits in a simple buffer matrix. Freshly synthesized THPQ and HHPQ were diluted in PBS followed by absorption and fluorescence measurements (Fig. 4). The detection sensitivity dilution using water in UV-compatible half-area plates; b Specific absorption curves after subtracting the Hepes buffer control data; c Fluorescence emission was measured between 500 and $700 \mathrm{~nm}$ after excitation at $460 \mathrm{~nm}$; d Fluorescence emission was measured at $620 \mathrm{~nm}$ after excitation between 360 and $560 \mathrm{~nm}$; White squares $(\square)$ represent cadaverine as substrate; White triangles $(\Delta)$ putrescine; White circles $(O)$ histamine and black line $(\boldsymbol{\square})$ no substrate. $M W C O$ molecular weight cut-off, $R F U$ relative fluorescence units

for absorption measurements is about the same for THPQ and HHPQ at approximately $2-4 \mu \mathrm{M}$. Fluorescent-based sensitivity limits are approximately $0.3 \mu \mathrm{M}$ for THPQ and $0.1 \mu \mathrm{M}$ for HHPQ, which is $20-40$-fold lower compared to absorption measurements. Using fluorescence measurements in clean buffer matrices $1 \mu \mathrm{M}$ THPQ and HHPQ consistently generate approximately 8000 and 21,000 RFUs (Fig. 4c and data not shown).

In the next experiment we determined the minimum concentration of rhDAO detectable with HHPQ versus Amplex Red using absorption and fluorescence measurements in PBS pH 7.4 with $0.05 \%$ human serum albumin (Fig. 5). The fluorescence-based analysis of HHPQ is at least 10-times more sensitive compared to absorption measurements (Fig. 5b versus 5a). Measurements of the fluorescence of resorufin are able to detect $1.2 \mathrm{ng} / \mathrm{ml} \mathrm{DAO}$ and are more 
A

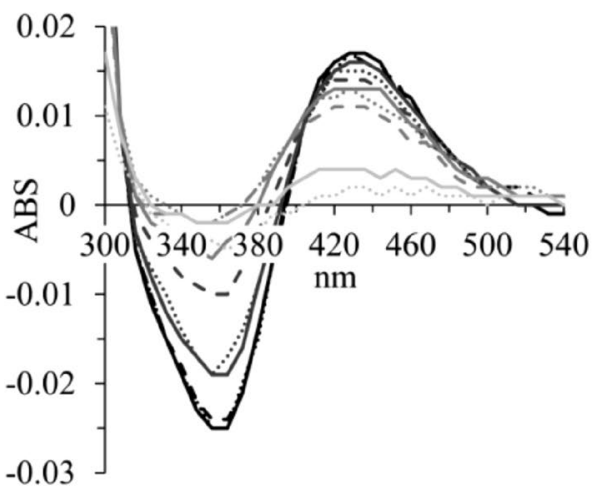

C

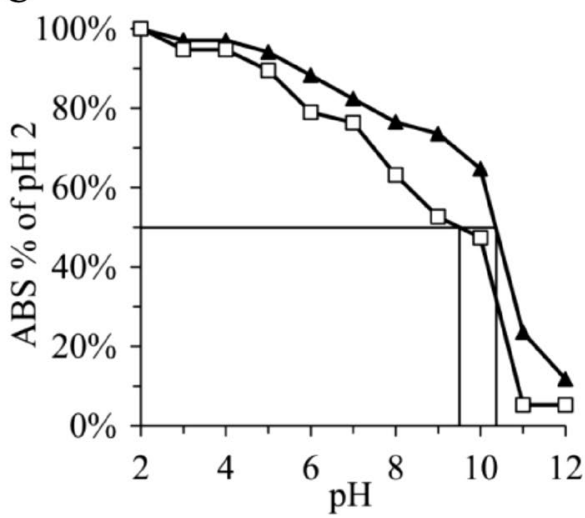

Fig. 3 Absorption and fluorescence of THPQ and HHPQ are $\mathrm{pH}$ dependent with $\mathrm{p} K_{\mathrm{a}}$ values between 8.5 and 10.5. Absorption (ABS) of freshly synthesized THPQ and HHPQ at $30 \mu \mathrm{M}$ after 1 to 13.3 dilutions with Britton Robinson buffer at $\mathrm{pH}$ levels between 2 and 12 was measured from 300 and $580 \mathrm{~nm}$. ABS data from Hepes buffer controls without substrate during synthesis were subtracted and the specific ABS of THPQ (a) and HHPQ (b) are presented. The numbers in Panel B below the $x$-axis represent the $\mathrm{pH}$ values; $\mathrm{pH} 2$, 3 and 4 data are shown as black, dotted and dashed lines, respec-

sensitive compared to using HHPQ detection, but by no more than threefold. Nevertheless, resorufin was detected using the monochromator with $16 \mathrm{~nm}$ bandwidth. For the excitation and emission of HHPQ we used a custom filter cube with 30 and $40 \mathrm{~nm}$ bandwidths. The ratio of the extinction coefficients between HHPQ $\left(2242 \mathrm{M}^{-1} \mathrm{~cm}^{-1}\right)$ and resorufin $\left(54,000 \mathrm{M}^{-1} \mathrm{~cm}^{-1}\right)$ is 24 . The squared correlation coefficients of the slopes of the regression lines plotting rhDAO in $\mathrm{ng} / \mathrm{ml}$ versus absorption or fluorescence units of HHPQ or resorufin is $>0.99$ in all 4 cases, indicating excellent linearity and rhDAO concentration dependency.

Before measuring HHPQ and resorufin in plasma we added $1 \mathrm{mM}$ oABA final concentration to 5 plasma samples from healthy volunteers and measured absorbance and fluorescence with the custom filter cube after trichloroacetic acid (TCA) precipitation (Fig. S5). Addition of oABA to the 5 plasma samples generated an absorption signal at $460 \mathrm{~nm}$ of
B

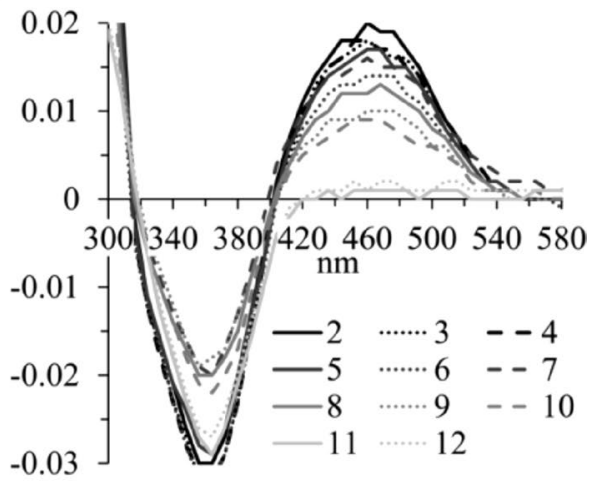

D

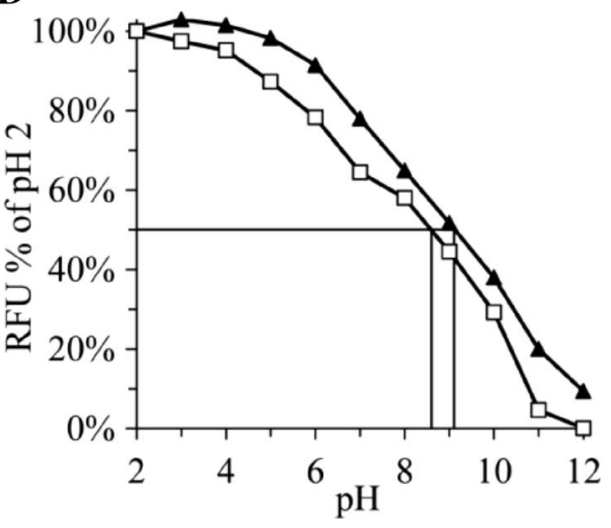

tively, and different grey shades are used for higher $\mathrm{pH}$ units; in $\mathbf{c}$ the ABS data from a at $430 \mathrm{~nm}$ (black triangles $\boldsymbol{\Delta}$ ) and (b) at $460 \mathrm{~nm}$ (white squares $\square$ ) are normalized based on the ABS values at $\mathrm{pH} 2.0$ (100\%); In d relative fluorescence units (RFU) measured using the custom filter cube with excitation at $440 \pm 15 \mathrm{~nm}$, a dichroic mirror with a cut-off at $550 \mathrm{~nm}$ and emission at $620 \pm 20 \mathrm{~nm}$ were normalized to the values at $\mathrm{pH} 2.0(100 \%)$. THPQ data are shown as black triangles $(\boldsymbol{\Delta})$ and HHPQ as white squares $(\square)$.

$104 \%$ ( $\mathrm{SD}=6.0 \%$ ) compared to the samples without oABA. The increase in fluorescence of $11 \%(\mathrm{SD}=2.9 \%)$ corresponds to approximately $2-3 \mu \mathrm{M}$ HHPQ. This signal might be caused by circulating delta-1-pyrroline-5-carboxylate and delta-1-piperideine-6-carboxylate. The fluorescence signal of HHPQ and of resorufin in plasma under comparable conditions shows that HHPQ detection is more sensitive compared to $\mathrm{H}_{2} \mathrm{O}_{2} / \mathrm{HRP} /$ Amplex Red coupling (Fig. 6a). Below $40 \mathrm{ng} / \mathrm{ml}$ rhDAO Amplex Red conversion seems totally inhibited. The fluorescence signals at $100 \mathrm{ng} / \mathrm{ml} \mathrm{rhDAO}$ are comparable. The flattening HHPQ signal at $300 \mathrm{ng} / \mathrm{ml}$ DAO might already indicate substrate consumption. The emission scan showed the expected fluorescence between 600 and $640 \mathrm{~nm}$ (Fig. 6b). Diamine oxidase in plasma of pregnant women can be readily measured after only $1 \mathrm{~h}$ incubation at $37^{\circ} \mathrm{C}$ (Fig. 6c), and the excitation and emission scans show the expected curves only after addition of cadaverine 
A

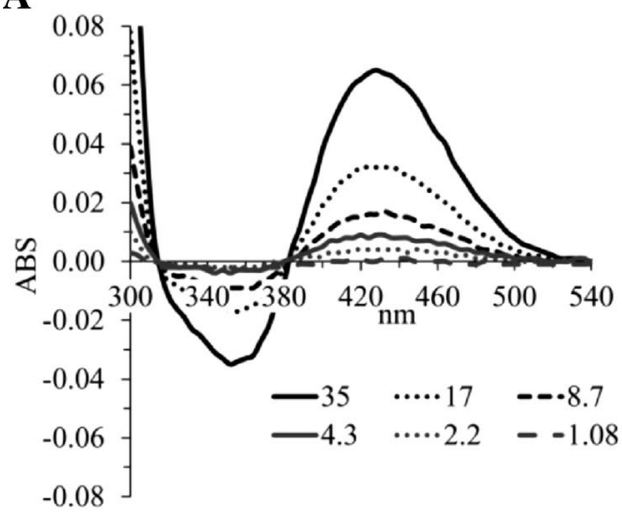

C

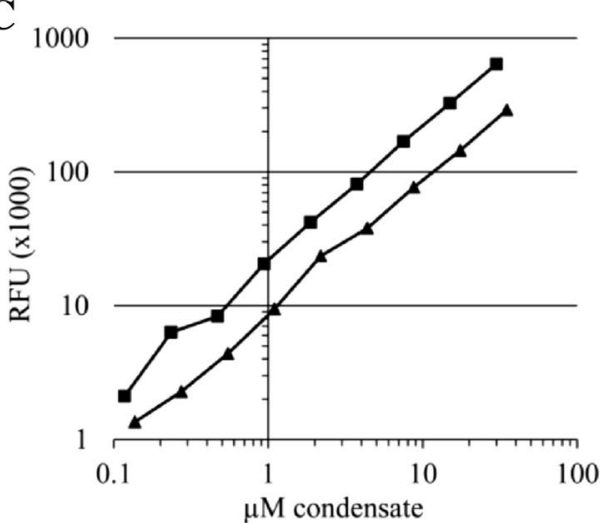

B

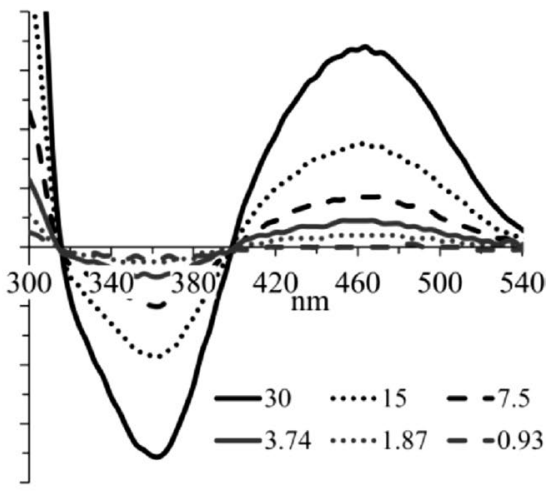

D

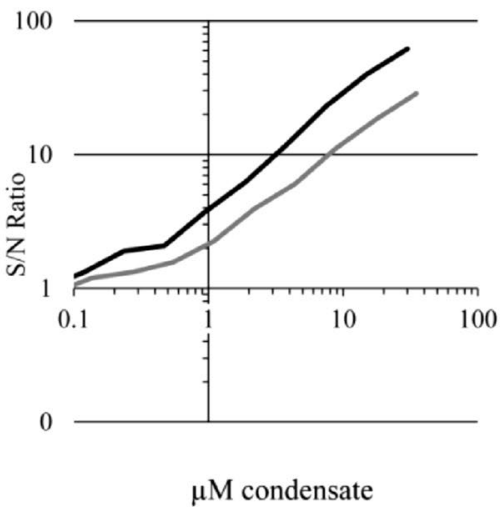

of the same samples was measured using the custom filter cube with excitation at $440 \pm 15 \mathrm{~nm}$, a dichroic mirror with a cut-off at $550 \mathrm{~nm}$ and emission at $620 \pm 20 \mathrm{~nm}$ and plotted against the THPQ (black triangles $\boldsymbol{\Delta}$ ) and HHPQ (black squares $\mathbf{\square}$ ) concentrations; The slopes for THPQ and HHPQ are 8280 and 21,390, respectively; d The signal over noise ratios were calculated for the fluorescence data shown in $\mathbf{c}$. $\mathrm{THPQ}=$ grey $; \mathrm{HHPQ}=$ black lines; $\mathrm{S} / \mathrm{N}=$ Signal/Noise

concentration circulating 10, 20 and 60 min after administration was $862(67) \mathrm{ng} / \mathrm{ml}$. Therefore, enzyme activity was $3.4 \mu \mathrm{mol} / \mathrm{min} / \mathrm{mg}$ DAO. In the same assay we used rhDAO as control in PBS with $0.05 \%$ HSA and using $1 \mu \mathrm{g} /$ $\mathrm{ml}$ DAO the RFUs from 60 to 90 min increased by only $7 \%$ indicating substrate consumption (data not shown). Therefore, we assumed that after $60 \min 93 \%$ or $186 \mu \mathrm{M}$ of CAD were consumed. This converts to $3.1 \mu \mathrm{mol} / \mathrm{min} /$ mg DAO. These values are close to our published values with rhDAO from $\mathrm{CHO}$ cells of 3.2 using absorption measurements of THPQ or to Elmore et al. (2002) of $2.9 \mu \mathrm{mol} /$ $\mathrm{min} / \mathrm{mg}$ with insect cell-derived rhDAO using $\mathrm{H}_{2} \mathrm{O}_{2} / \mathrm{HRP}$ coupling [1, 18]. All calculations were performed using $\mathrm{V}_{\max }$ conditions with no corrections for the minimal $K_{\text {cat }}$ differences between PUT and CAD [1]. Conversion calculations with underlying assumptions have been published [7]. The conversion of several published activity measurements into $\mathrm{ng} / \mathrm{ml}$ are close to the DAO ELISA measured antigen concentrations [7]. 

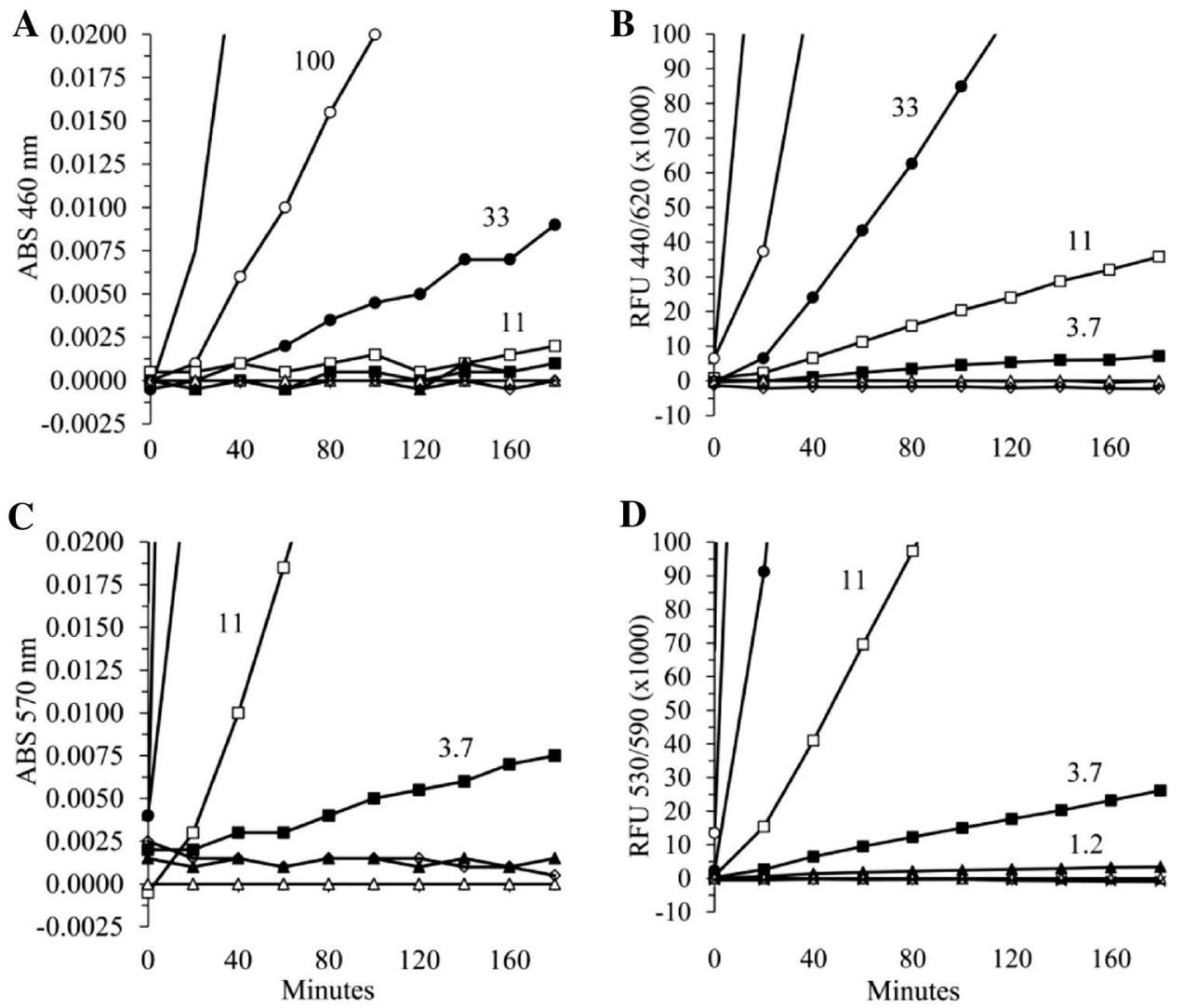

Fig. 5 Fluorescence measurements of DAO activity using HHPQ detection in comparison to hydrogen peroxide $\left(\mathrm{H}_{2} \mathrm{O}_{2}\right)$ /horseradish peroxidase (HRP)/Amplex Red coupling. a Six rhDAO concentrations were incubated with $1 \mathrm{mM}$ oABA and $100 \mu \mathrm{M}$ cadaverine in PBS (pH 7.4 containing $0.05 \%$ human serum albumin) at $37{ }^{\circ} \mathrm{C}$ and absorption (ABS) measured at $460 \mathrm{~nm}$ every $20 \mathrm{~min}$ for $3 \mathrm{~h}$; b Fluorescence (RFU = relative fluorescence units) of the same samples was measured using the custom filter cube with excitation at $440+/-15 \mathrm{~nm}$, a dichroic mirror with a cut-off at $550 \mathrm{~nm}$ and emission at $620+/-20 \mathrm{~nm}$; $\mathbf{c}$ The same samples described in a were incu-

Southren (1964) measured DAO activity in 15 healthy women at parturition employing the radioactive ${ }^{14} \mathrm{C}$-putrescine assay with $95 \%$ plasma [39]. Using the average plateau activity of approximately 420 units and the unit definition of $0.45 \mathrm{pmol} / \mathrm{ml} / \mathrm{min}$ at $37^{\circ} \mathrm{C}$ the DAO activity would be $189 \mathrm{pmol} / \mathrm{ml} / \mathrm{min}$. In the 10 pregnancy plasma samples at parturition we measured a mean DAO activity of $191 \mathrm{pmol} / \mathrm{ml} /$ min using 21,000 specific RFUs per $\mu \mathrm{M}$ substrate consumption (Figs. 4c, 6c). Cadaverine was unlikely consumed after $60 \mathrm{~min}$, because the mean DAO concentration in the pregnancy samples was $122 \mathrm{ng} / \mathrm{ml}$.

bated not with oABA but with $1 \mu \mathrm{g} / \mathrm{ml}$ HRP and $100 \mu \mathrm{M}$ Amplex Red and ABS was measured at $570 \mathrm{~nm}$; d The RFUs of the samples shown in Panel $\mathrm{C}$ were determined using excitation at $530 \mathrm{~nm}$ and emission at $590 \mathrm{~nm}$. All samples were run in duplicate and the means are shown. The following symbols represent $300(\boldsymbol{\square}) ; 100(\bigcirc) ; 33$ $(\mathbf{O}) ; 11(\square) ; 3.7(\mathbf{\square}) ; 1.23(\mathbf{\Delta})$ and $0(\Delta) \mathrm{ng} / \mathrm{ml} \mathrm{rhDAO}$ and are partially shown in the panels; the white diamonds $(\diamond)$ represent no DAO and no cadaverine. The ABS data have been normalized to the data using $0 \mathrm{ng} / \mathrm{ml} \mathrm{rhDAO}$

\section{Discussion}

Although DAO celebrated already its 90th birthday, the physiological role of this enzyme is unclear [27]. Large animal data in pigs and sheep support the role of DAO in the protection from exogenous histamine [28, 29], but conclusive human data showing that increased exogenous histamine sensitivity is strongly associated with lower DAO activity are not available. The role of DAO in the degradation of endogenously-released histamine, for example 

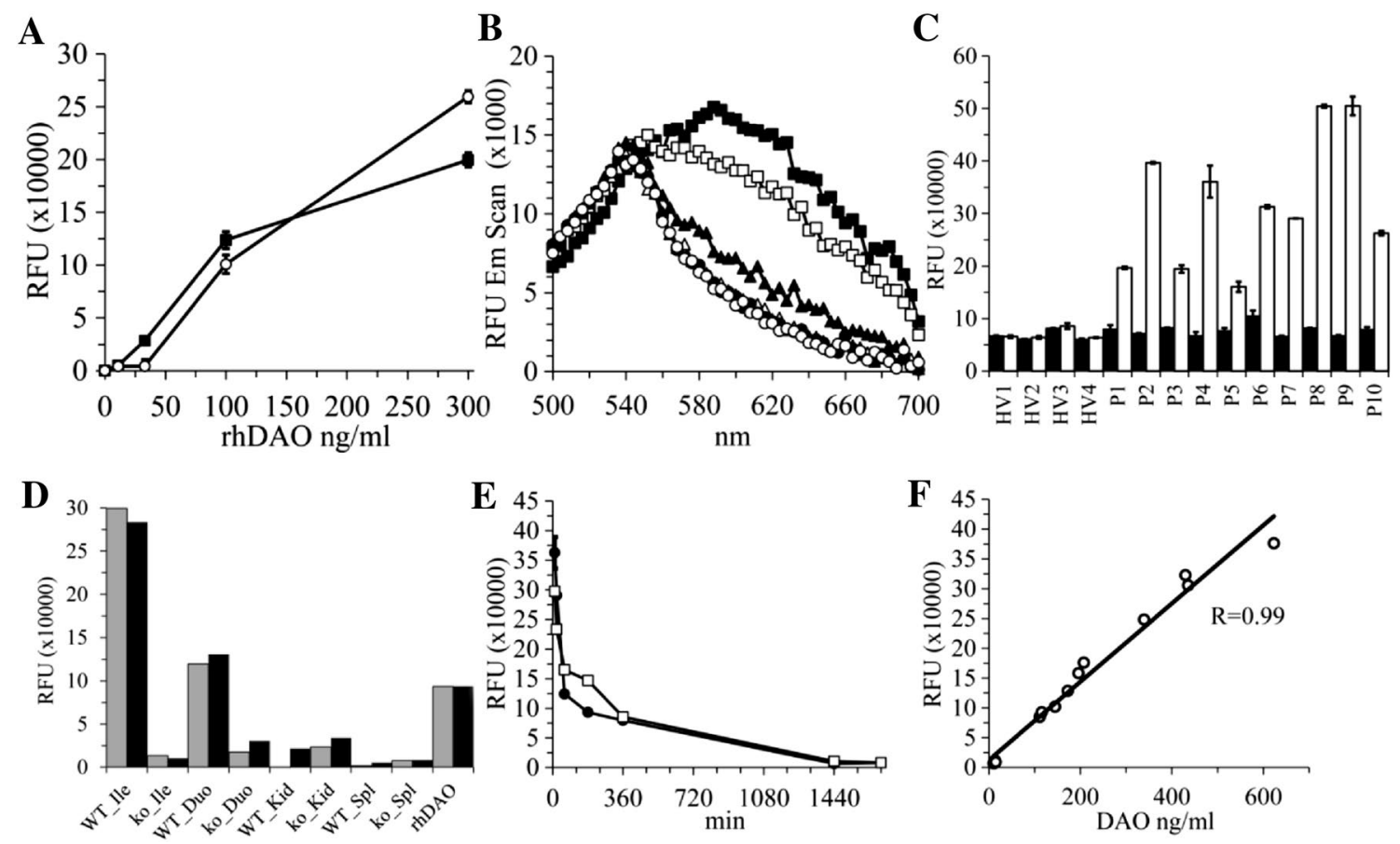

Fig. 6 The HHPQ fluorophore can be used to measure endogenous and exogenous DAO activity in complex matrices like human and rat plasma or mouse tissue extracts. a Indicated rhDAO concentrations were incubated in EDTA plasma with $200 \mu \mathrm{M}$ cadaverine $(\mathrm{CAD})$ for $3 \mathrm{~h}$ at $37^{\circ} \mathrm{C}$. The black square (ם) series contained $1 \mathrm{mM}$ oABA and the parallel-prepared white circles (O) $100 \mu \mathrm{M}$ Amplex Red and $1 \mu \mathrm{g} / \mathrm{ml}$ horseradish peroxidase. After trichloroacetic acid (TCA) protein precipitation the $\mathrm{pH}$ was adjusted to 4.0 for measuring HHPQ and to 7.8 for measuring resorufin. Relative fluorescence units (RFUs) were determined using the custom filter for HHPQ and the monochromator using excitation at $550 \mathrm{~nm}$ and emission at $590 \mathrm{~nm}$ for resorufin. The mean of duplicates $(+/-$ SEM) are presented; b Emission scans of HHPQ after excitation at $460 \mathrm{~nm}$. The following symbols represent $300(\boldsymbol{\square}), 100(\square), 33(\mathbf{\Delta}), 11(\Delta), 0(\mathbf{\bullet}) \mathrm{ng} /$ $\mathrm{ml}$ rhDAO; White circles $(\mathrm{O})$ show fluorescence without DAO and without oABA. c Four EDTA plasma samples from healthy volunteers (HV1-HV4) and 10 EDTA plasma samples from 3rd trimester pregnancies were incubated with $1 \mathrm{mM}$ oABA and either PBS (black

during anaphylaxis or mast cell activation, is unknown. The strong increase in DAO activity and antigen concentrations during pregnancy in animals and humans does not have an ascribed function, and might be simply an epiphenomenon of the excessive expression and secretion of hDAO from fetal extravillous trophoblasts $[4,30]$.

Despite the lack of a clear understanding of the physiological and pathophysiological roles of DAO, a partially purified porcine kidney DAO was used for the treatment of different allergic conditions soon after its discovery [31]. Efficacy data or data showing any clinically relevant benefit using this preparation have not been published. Limited efficacy could be due to the rapid clearance from the circulation or the presence of an endogenous DAO inhibitor. Several decades ago only DAO activity assays were available but this columns) or $200 \mu \mathrm{M} \mathrm{CAD}$ (white columns) for $1 \mathrm{~h}$ at $37^{\circ} \mathrm{C}$. After TCA precipitation and $\mathrm{pH}$ adjustment to 4.0 , RFUs were measured using the custom filter cube. The means of duplicates $(+/-$ SEM) are shown. d Protein extracts of different organs from wild-type and DAO knock-out mice at $500 \mu \mathrm{g} / \mathrm{ml}$ were incubated with $1 \mathrm{mM}$ oABA and either water, $400 \mu \mathrm{M}$ CAD or $400 \mu \mathrm{M}$ CAD plus $20 \mu \mathrm{M}$ aminoguanidine (AG); RFUs were measured using the custom filter cube after $60 \mathrm{~min}$ at $37^{\circ} \mathrm{C}$. Black and grey columns represent the specific RFUs after subtracting the RFUs from the incubations without CAD or with CAD plus AG, respectively. Ile Ileum, Duo Duodenum, Kid Kidney, $S p l$ Spleen, rhDAO at $500 \mathrm{ng} / \mathrm{ml}$, WT wildtype mice; $k o$ DAO knockout mice; e $1 \mathrm{mg} / \mathrm{kg}$ rhDAO was intravenously injected into two rats and plasma collected at different time points. Plasma samples were tenfold diluted and incubated with $1 \mathrm{mM}$ oABA and $200 \mu \mathrm{M} \mathrm{CAD}$ for $90 \mathrm{~min}$ at $37^{\circ} \mathrm{C}$. RFUs were measured after TCA precipitation. The means $(+/-\mathrm{SEM})$ of duplicates are shown. $\mathbf{f}$ Correlation between RFUs (Panel e) and DAO antigen concentrations measured using our human DAO ELISA

might not have been sufficient. Antigen concentrations could not be measured. Pharmacokinetic data about this DAO formulation have not been published.

To better understand any functional role of hDAO adequate tools are necessary to measure not only antigen concentration but also activity. Nevertheless, the use of radioactive substrates is discouraged in today's laboratory environment for multiple reasons and $\mathrm{HRP} / \mathrm{H}_{2} \mathrm{O}_{2}$-coupling might be as sensitive as the radioactive putrescine assay [5], but $\mathrm{HRP} / \mathrm{H}_{2} \mathrm{O}_{2}$-generated radicals generated as correlate for DAO activity might be avidly trapped by the high concentrations of antioxidants like uric acid, Vitamin C or Vitamin $\mathrm{E}$ or $\mathrm{H}_{2} \mathrm{O}_{2}$ degraded by enzymes in complex matrices like plasma or tissue extracts. In Fig. 1 we use plasma to provide strong evidence that antioxidant activity severely 
compromises activity data using $\mathrm{HRP} / \mathrm{H}_{2} \mathrm{O}_{2}$-coupling. We were actively searching for an alternative assay with increased sensitivity compared to absorption measurements described by Holmstedt and Tham [11] and McEwen [12] but independent of $\mathrm{H}_{2} \mathrm{O}_{2}$.

We confirm the proposed structures of the condensate between $\mathrm{OABA}$ and delta-1-pyrroline or delta-1-piperideine using mass spectrometry and show that THPQ and HHPQ are not only chromophores but also fluorophores increasing the sensitivity of the Holmstedt assay by at least tenfold. The general scheme of this assay using cadaverine as substrate including chemical structures is presented in Fig. 7.

The cadaverine-generated HHPQ consistently shows $250 \%$ higher fluorescence signal intensities compared to THPQ, which might be explained by the 6-ring structure compared to the delta-1-pyrroline-generated THPQ. At the moment we have neither data nor a conclusive hypothesis regarding the relatively large Stoke shifts of $5610 \mathrm{~cm}^{-1}$ $(160 \mathrm{~nm})$ and $6598 \mathrm{~cm}^{-1}(180 \mathrm{~nm})$ for HHPQ and THPQ, respectively. Median Stoke shifts of standard fluorescent dyes are $659 \mathrm{~cm}^{-1}(24 \mathrm{~nm} ; n=31)$.

Using tissue extracts of wild-type and DAO knock-out mice we were able to show that the fluorescence signals with activity-blocked DAO and the signal without addition of cadaverine as substrate were very similar. This indicates that no other enzymes can efficiently oxidize cadaverine and generate delta-1-piperideine. The endogenous polyamine putrescine is likely diluted too highly during tissue homogenization and protein extract preparation to cause significant

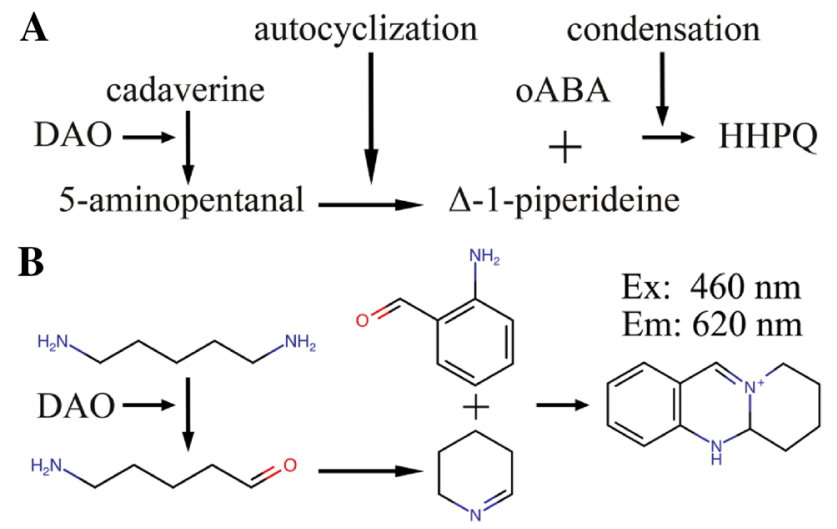

Fig. 7 Scheme for the generation of the quinazoline fluorophore HHPQ from cadaverine via DAO oxidation. a After DAO oxidation of cadaverine (pentane-1,5-diamine) the released aldehyde 5-aminopentanal autocyclizes to delta-1-piperideine (2,3,4,5-tetrahydro-pyridine), which spontaneously condensates with ortho-aminobenzaldehyde (oABA) generating HHPQ or 5,5a,6,7,8,9-hexahydropyrido[2,1- ${ }^{\mathrm{b}}$ ] quinazoline-10-ium. The release of $\mathrm{H}_{2} \mathrm{O}_{2}$ and $\mathrm{NH}_{3}$ during deamination, the release of $\mathrm{H}_{2} \mathrm{O}$ during autocyclization and $\mathrm{OH}^{-}$after condensation and rearrangement are not shown; b Chemical structures; Ex Excitation, Em Emission; For the scheme using putrescine as substrate see Supplement fluorescence after condensation with oABA. Spermine and spermidine do not generate a fluorescence signal in this assay.

The background signal in the various tissue extracts might be caused by the presence of delta-1-pyrroline-5-carboxylate and delta-1-piperideine-6-carboxylate. These Schiff bases generated within proline and lysine metabolic pathways condensate with oABA and might contribute to the background signal [32-34]. Nevertheless, under normal conditions the concentrations of both metabolites are likely low, because they are converted by reductases and dehydrogenases to metabolites unable to condensate with oABA. Individuals with very rare enzymatic defects like antiquitin deficiency or hyperprolinemia II show increased oABA condensatespecific absorption in urine [35-37] and likely also in tissue extracts, but we are not aware of published data using tissue samples.

At low $\mathrm{pH}$ reduced NADH but not NAD + condensates with oABA [38]. A quinazoline derivative similar to HHPQ was likely generated with an absorption peak of approximately $460 \mathrm{~nm}$. There are no publications regarding whether the NADH/oABA condensates also fluoresce. These condensates might be generated after 5\% TCA precipitation $(\mathrm{pH}$ below 2) in tissue extracts or plasma. Except for really strong DAO substrate-independent fluorescence the background signal is not a real concern, because the assay should always be performed with and without addition of cadaverine and possibly aminoguanidine.

This new fluorescent assay allows the sensitive detection of DAO activity without the use of radioactive substrates and irrespective of the antioxidant capacity of tissue extracts or plasma. It is also simple to perform and directly measures the autocyclization products of natural substrates. This method could be also adjusted to quantify submicromolar concentrations of putrescine or cadaverine generated by ornithine or lysine decarboxylases. The enzymatic activity of polyamine oxidase generating putrescine from spermidine or acetyl-spermidine might be also measured. Derivatives of delta-pyrroline like delta-1-pyrroline-2-carboxylate or similarly delta-1-piperideine-2-carboxylate might also fuse with oABA allowing fluorescent quantification with this assay. Liquid chromatographic separation of samples followed by fluorescence detection of THPQ or HHPQ likely increases the sensitivity several-fold, but also causes some of the simplicity of the assay to be lost.

In conclusion, we are now able to measure human DAO antigen concentrations with the corresponding activity and should be able to detect circumstances under which the DAO antigen concentration is high but the activity is low. This is important for investigations of possible DAO inhibitors among administered drugs. This assay is also essential to elucidate the mechanism behind the recently published data during severe mast cell activation events, where DAO 
activity was severely compromised despite high antigen concentrations [37]. We need to better understand how DAO activity can be inhibited, preferably before rhDAO is used for the treatment of conditions with excess circulating histamine such as anaphylaxis or mast cell activation syndrome.

\begin{abstract}
Acknowledgements Open access funding provided by Medical University of Vienna. Norbert Wahler (Szabo-Scandic; Vienna) is greatly acknowledged for his excellent support with the Synergy H1 Microplate reader especially for fluorescence measurements. We thank Sophie Pils for providing EDTA plasma samples from women in their late 3rd trimester and Marton Siklos for help with proper IUPAC naming of HHPQ and THPQ. TB acknowledges Gert Van der Zwan for teaching him a deeper understanding of absorption and fluorescence measurements and stimulating discussions about the reason for the large Stoke shifts of THPQ and HHPQ. We are indebted to Sarah Ely for the final polish in the proper usage of the English language.
\end{abstract}

Author contributions TB designed the experiments, analyzed the data and wrote the manuscript. MK established the DAO knock-out (KO) mouse colony, prepared tissue protein extracts from wild-type and DAO $\mathrm{KO}$ mice and performed the DAO activity assay; EG expressed, characterized and purified rhDAO; KP performed most in vitro experiments and analyzed the data; MR and KS performed in vivo mouse and rat experiments; KK identified HHPQ and THPQ using mass spectrometry and analyzed the data; NB and $\mathrm{BJ}$ provided comments during manuscript writing. All authors provided critical input during manuscript writing and were involved in the finalization of the manuscript

\section{Funding None.}

\section{Compliance with ethical standards}

Conflict of interest The authors declare that they have no conflict of interests.

Open Access This article is licensed under a Creative Commons Attribution 4.0 International License, which permits use, sharing, adaptation, distribution and reproduction in any medium or format, as long as you give appropriate credit to the original author(s) and the source, provide a link to the Creative Commons licence, and indicate if changes were made. The images or other third party material in this article are included in the article's Creative Commons licence, unless indicated otherwise in a credit line to the material. If material is not included in the article's Creative Commons licence and your intended use is not permitted by statutory regulation or exceeds the permitted use, you will need to obtain permission directly from the copyright holder. To view a copy of this licence, visit http://creativecommons.org/licenses/by/4.0/.

\section{References}

1. Elmore BO, Bollinger JA, Dooley DM. Human kidney diamine oxidase: heterologous expression, purification, and characterization. J Biol Inorg Chem. 2002;7:565-79.

2. Biegański T, Kusche J, Lorenz W, Hesterberg R, Stahlknecht CD, Feussner KD. Distribution and properties of human intestinal diamine oxidase and its relevance for the histamine catabolism. Biochim Biophys Acta. 1983;756:196-203.

3. Schwelberger HG, Hittmair A, Kohlwein SD. Analysis of tissue and subcellular localization of mammalian diamine oxidase by confocal laser scanning fluorescence microscopy. Inflamm Res. 1998;47(Suppl 1):S60-61.

4. Velicky P, Windsperger K, Petroczi K, Pils S, Reiter B, Weiss $\mathrm{T}$, et al. Pregnancy-associated diamine oxidase originates from extravillous trophoblasts and is decreased in early-onset preeclampsia. Sci Rep. 2018;8:6342. https://doi.org/10.1038/s4159 8-018-24652-0.

5. Okuyama T, Kobayashi Y. Determination of diamine oxidase activity by liquid scintillation counting. Arch Biochem Biophys. 1961;95:242-50.

6. Tufvesson G, Tryding N. Determination of diamine oxidase activity in normal human blood serum. Scand J Clin Lab Invest. 1969;24:163-8.

7. Boehm T, Pils S, Gludovacz E, Szoelloesi H, Petroczi K, Majdic $\mathrm{O}$, et al. Quantification of human diamine oxidase. Clin Biochem. 2017;50:444-51. https://doi.org/10.1016/j.clinbioche m.2016.12.011.

8. Fogel WA, Ulatowska M, Adach K, Osińska Z. A sum of 14C-putrescine metabolites as a measure of DAO activity Column chromatography assay. Agents Act. 1985;16:99-101.

9. Bardsley WG, Crabbe MJC, Shindler JS, Ashford JS. Oxidation of p-dimethylaminomethylbenzylamine by pig kidney diamine oxidase. A new method for spectrophotometric assay. Biochem J. 1972;127:875-9.

10. Schöpf C, Oechler F. Zur Frage der Biogenese des Vasicins (Peganins). Die Synthese des Desoxyvasicins unter physiologischen Bedingungen. Justus Liebigs Ann Chem. 1936;523:1-29. https:// doi.org/10.1002/jlac.19365230102.

11. Holmstedt B, Tham R. A spectrophotometric method for determination of diamine oxidase (DAO) activity. Acta Physiol Scand. 1959;45:152-63.

12. McEwen CM. Serum amine oxidases in pregnancy. J Lab Clin Med. 1964;64:540-7.

13. Snyder SH, Hendley ED. A simple and sensitive fluorescence assay for monoamine oxidase and diamine oxidase. J Pharmacol Exp Ther. 1968;163:386-92.

14. Schwelberger HG, Feurle J. Luminometric determination of amine oxidase activity. Inflamm Res. 2007;56(Suppl 1):S53-54.

15. Halliwell B, Gutteridge JMC. The antioxidants of human extracellular fluids. Arch Biochem Biophys. 1990;280:1-8.

16. Boehm T, Reiter B, Ristl R, Petroczi K, Sperr W, Stimpfl T, et al. Massive release of the histamine-degrading enzyme diamine oxidase during severe anaphylaxis in mastocytosis patients. Allergy. 2019;74:583-93. https://doi.org/10.1111/all.13663.

17. Sattler J, Lorenz W. Intestinal diamine oxidases and enteralinduced histaminosis: studies on three prognostic variables in an epidemiological model. J Neural Transm Suppl. 1990;32:291-314.

18. Gludovacz E, Maresch D, Bonta M, Szöllösi H, Furtmüller PG, Weik R, et al. Characterization of recombinant human diamine oxidase (rhDAO) produced in Chinese Hamster Ovary (CHO) cells. J Biotechnol. 2016;227:120-30.

19. Cham BE, Knowles BR. A solvent system for delipidation of plasma or serum without protein precipitation. J Lipid Res. 1976;17:176-81.

20. Britton HTS, Robinson RA. Universal buffer solutions and the dissociation constant of veronal. J Chem Soc. 1931. https://doi. org/10.1039/JR9310001456.

21. Kilkenny C, Browne W, Cuthill IC, Emerson M, Altman DG, NC3Rs Reporting Guidelines Working Group. Animal research: reporting in vivo experiments: the ARRIVE guidelines. Br J Pharmacol. 2010Animal;160:1577-9.

22. Bienert GP, Schjoerring JK, Jahn TP. Membrane transport of hydrogen peroxide. Biochim Biophys Acta. 2006;1758:994-1003.

23. Rönnberg AL, Hansson C, Drakenberg T, Håkanson R. Reaction of histamine with o-phthalaldehyde: isolation and analysis of the fluorophore. Anal Biochem. 1984;139:329-37. 
24. Yoshimura T, Kaneuchi T, Miura T, Kimura M. Kinetic analysis of the fluorescence reaction of histamine with orthophthalaldehyde. Anal Biochem. 1987;164:132-7.

25. Shore PA, Burkhalter A, Cohn VH. A method for the fluorometric assay of histamine in tissues. J Pharmacol Exp Ther. 1959;127:182-6.

26. Thorrez L, Deun KV, Tranchevent L-C, Lommel LV, Engelen K, Marchal K, et al. Using ribosomal protein genes as reference: a tale of caution. PLoS One. 2008;3:e1854.

27. Best $\mathrm{CH}$. The disappearance of histamine from autolysing lung tissue. J Physiol. 1929;67:256-63.

28. Sjaastad ÖV. Potentiation by Aminoguanidine of the sensitivity of sheep to histamine given by mouth. Effect of aminoguanidine on the urinary excretion of endogenous histamine. Q J Exp Physiol Cogn Med Sci. 1967;52:319-30.

29. Sattler J, Häfner D, Klotter HJ, Lorenz W, Wagner PK. Foodinduced histaminosis as an epidemiological problem: plasma histamine elevation and haemodynamic alterations after oral histamine administration and blockade of diamine oxidase (DAO). Agents Act. 1988;23:361-5.

30. Kobayashi Y. Plasma diamine oxidase titres of normal and pregnant rats. Nature. 1964;203:146-7. https://doi.org/10.1038/20314 $6 \mathrm{a} 0$.

31. Laymon CW, Cumming H. Histaminase in the treatment of urticaria and atopic dermatitis. J Invest Dermatol. 1939;2:301-12.

32. Strecker HJ. The interconversion of glutamic acid and proline. I. The formation of delta1-pyrroline-5-carboxylic acid from glutamic acid in Escherichia coli. J Biol Chem. 1957;225:825-34.

33. Soda K, Misono H, Yamamoto T. L-Lysine:alpha-ketoglutarate aminotransferase. I. Identification of a product, delta-1-piperideine-6-carboxylic acid. Biochemistry. 1968;7:41029. https://doi.org/10.1021/bi00851a045.

34. Fothergill JC, Guest JR. Catabolism of 1-Lysine by Pseudomonas aeruginosa. J Gen Microbiol. 1977;99:139-55. https://doi. org/10.1099/00221287-99-1-139.

35. Applegarth DA, Ingram P, Hingston J, Hardwick DF. Hyperprolinemia Type II. Clin Biochem. 1974;7:14-28.

36. Flynn MP, Martin MC, Moore PT, Stafford JA, Fleming GA, Phang JM. Type II hyperprolinaemia in a pedigree of Irish travellers (nomads). Arch Dis Child. 1989;64:1699-707.

37. Boehm T, Hubmann H, Petroczi K, Mathis D, Klavins K, Fauler $\mathrm{G}$, et al. Condensation of delta-1-piperideine-6-carboxylate with ortho-aminobenzaldehyde allows its simple, fast, and inexpensive quantification in the urine of patients with antiquitin deficiency. $\mathrm{J}$ Inherit Metab Dis. 2020. https://doi.org/10.1002/jimd.12214.

38. Larson RL, Broquist HP. A color reaction between reduced pyridine nucleotides and $O$-aminobenzaldehyde of potential analytical use. Anal Biochem. 1963;5:255-8. https://doi.org/10.1016/00032697(63)90122-2.

39. Southren AL, Kobayashi Y, Sherman DH, Levine L, Gordon G, Weingold AB. Diamine oxidase in human pregnancy: plasma diamine oxidase in nonpregnant and normal pregnant patients. Am J Obstet Gynecol. 1964;89:199-203.

Publisher's Note Springer Nature remains neutral with regard to jurisdictional claims in published maps and institutional affiliations. 